\title{
El régimen jurídico de los actos administrativos del Banco de la República, ¿derecho administrativo o derecho económico?
}

\author{
Carlos F. Forero Hernández
}

A mi gran maestro, Dr. Hernando A. Hernández Quintero

\begin{abstract}
Resumen: El objeto de este escrito es presentar a la comunidad académica la conveniencia de hablar de derecho económico, y no de derecho administrativo, cuando nos referimos al régimen jurídico de los actos administrativos del Banco de la República; entendiendo por derecho económico el derecho de la intervención del Estado en la economía, o como el derecho mixto que lo permea, tanto el derecho público como el derecho privado. Este tema tiene un enfoque interdisciplinar que vincula el derecho y la economía.
\end{abstract}

Palabras claves: Banco de la República, derecho económico.

\section{Introducción}

El artículo 371 de la Carta Política (1991) dispuso que el Banco de la República sería una persona jurídica de derecho público, con autonomía: 1) administrativa, 2) patrimonial y 3) técnica, y con un régimen jurídico legal propio, cuyas principales funciones básicas se concretan en: a) regular: 1) la moneda, 2) los cambios internacionales y 3 ) el crédito; b) emitir la moneda legal; c) administrar las reservas internacionales; d) ser prestamista de última instancia y banquero de los establecimientos de crédito; y e) servir como agente fiscal del Gobierno; funciones que deben ejercerse en "coordinación con la política económica general” (artículo 371 de la Constitución Política, 1991).

\footnotetext{
*Magíster en Derecho Administrativo -línea de profundización: Derecho Público Económico- de la Universidad Libre (Pereira). Asesor en Derecho Presupuestal y Contratación Estatal.
} 
Con fundamento en la norma constitucional citada, el legislador emite la Ley 31 de 1992, reglamentada por el Decreto 2520 de 1993, "por el cual se expide los Estatutos del Banco de la República” (Gaviria, 1999, p. 70). En relación con el régimen jurídico de los actos administrativos y de los contratos del Banco de la República, se tratarán de actos administrativos sometidos al derecho administrativo cuando sean funciones públicas, y de actos y contratos privados, en el evento de relaciones jurídicas comerciales, civiles y laborales.

En la teoría general del acto administrativo se ha identificado que a estos se les deben aplicar instituciones propias de derecho administrativo (Rodríguez, 2000). No obstante, hay una corriente doctrinaria $-\mathrm{y}$ es la que compartimos-, la cual afirma que dichos actos no quedan excluidos en cuanto a su aplicación instituciones de derecho privado, tales como: 1) la teoría del acto jurídico, 2) de la personalidad jurídica, y 3) de la irretroactividad (Sánchez, 1995). Significa que a los actos administrativos se les deben aplicar instituciones de derecho público y de derecho privado.

Si a los actos administrativos del Banco de la República se les aplican instituciones de derecho privado y de derecho público entonces nos conduce a señalar que no es conveniente hablar de derecho administrativo, sino de derecho económico, cuando nos referimos al régimen jurídico de los actos administrativos del mencionado Banco, y de acuerdo con la doctrina, el derecho económico es el derecho mixto con relación al derecho privado y al derecho público (Barón, 2016); igualmente es definido como el derecho de la intervención del Estado en la economía (Ariño, 2003). Estas reflexiones son precisamente el objeto del presente artículo, veamos.

\section{Derecho administrativo y derecho económico. Ubicación del tema \\ 1.1. Definición doctrinal de la institución: derecho administrativo}

Del derecho administrativo se han concedido tantas definiciones como autores se han ocupado del tema. Algunos señalan que el derecho administrativo es el derecho de la Administración pública (Ayala, 2009) o como el derecho de la función administrativa (Montaña, 2017).

El constitucionalista Younes Moreno (2016), lo define como: "La rama del derecho público concerniente a la Administración" (p. 3). En mismo sentido lo entiende el tratadista francés, Jean Rivero (2006). El profesor de la Universidad Libre Amado Abril (2017) lo define como una ciencia jurídica que se encarga de estudiar la institución Administración pública principalmente en sus tres componentes: 1) la función administrativa, 2) la función pública y 3 ) la gestión pública. 
Entre otras nociones que no escapan de mencionar la institución se encuentran: Administración pública, como objeto de estudio del derecho administrativo (Fraga, 2000); se entiende por esta, de acuerdo con el tratadista mexicano Guerrero Orozco (1997), como "la actividad del Estado" (p. 24), esto es, referida a la función administrativa (criterio material) (Ayala, 1994).

De esta manera, la Administración pública involucra todas las funciones administrativas que ejercen los distintos órganos del Estado, sin importar a cuál rama del Poder Público pertenezcan, incluyendo las funciones administrativas ejercidas por particulares y autorizadas por la ley; funciones en las cuales se deben aplicar los principios consagrados en el artículo 209 de la Carta Política (1991) como son: "Igualdad, moralidad, eficacia, economía, celeridad, imparcialidad y publicidad" (artículo 209 de la Constitución Política, 1991).

Dichas funciones administrativas se relacionan con la actividad administrativa (Montaña, 2017), la que conduce a la actuación administrativa (Ayala, 1994), y la cual se manifiesta a través de actos administrativos, operaciones administrativas, hechos administrativos, omisiones administrativas, como también a través de contratos (Rodríguez, 2000), actuaciones estas que están sometidas a la teoría del control judicial (Palacio, 2000).

No sobra mencionar que el conjunto de materias relacionadas con la organización del Estado y de la función administrativa debe estudiarse a la luz de la Ley 489 de 1998, estatuto de mayor importancia para el estudio del derecho administrativo (Vidal, 2004).

Una vez precisada la noción doctrinal sobre la institución derecho administrativo, pasemos ahora a hablar sobre los factores que dan lugar a la trasformación de este en derecho económico, un nuevo paradigma de las ciencias sociales. Corresponde advertir que dicha transformación no implica el desaparecimiento de la teoría del control judicial.

Se han identificado dos fenómenos en los cuales consideramos que dan lugar a la trasformación del derecho administrativo en derecho económico, a saber: 1) La ruptura de la ecuación derecho administrativo-Administración pública y 2) la huida del derecho administrativo hacia al derecho privado (pueden existir otros fenómenos adicionales).

De acuerdo con el primero, el tratadista argentino Juan Carlos Cassagne (1999) ha mencionado que la ruptura se presenta por "la injerencia progresiva del derecho administrativo contemporáneo sobre esferas de actuación reservadas anteriormente con exclusividad al derecho privado" (p. 107). Dicha ruptura surge debido a la evidente participación de personas jurídicas privadas 
(y personas naturales) que efectúan funciones administrativas; también por la notoria participación de empresas privadas para la prestación de servicios públicos. Es de anotar, que al evidenciar que las empresas privadas cumplen funciones administrativas, no significa, como es obvio, que perderán su naturaleza de empresa privada; siguen siendo empresas de derecho privado.

De acuerdo con la segunda, es decir, de la huida del derecho administrativo hacia el derecho privado, el profesor de la Universidad de Medellín Molina Betancur (2007) nos ha dado a entender que hay normatividades en las cuales se señalan que para determinadas áreas relacionadas con la Administración pública, no es posible aplicar de manera exclusiva normas de derecho público, pues también corresponde observar con mayor rigor normas de derecho privado, como es el caso, por ejemplo, del régimen jurídico de la contratación estatal previsto en la Ley 80 de 1993, disposición esta que está fuertemente impregnada del derecho privado.

$\mathrm{Al}$ concebir por contratos estatales aquellos negocios jurídicos celebrados por el Estado, este último se convierte en competidor, al igual que los particulares, y se comporta como ellos; el Estado actúa como Estado empresario. Acá tenemos otro ejemplo de la huida del derecho administrativo hacia al derecho privado en la medida en que el Estado participa de manera significativa en las relaciones privadas.

El abogado y máster en Derecho Económico Barón Barrera (2016), al realizar un profundo estudio sobre la huida del derecho administrativo hacia el derecho privado desde el neoliberalismo como en el intervencionismo, concluyó que dicho fenómeno está ligado al modelo de desarrollo, pues en el neoliberalismo el derecho administrativo huye al derecho privado, pero, sin abandonar el primero sino, que se aplica con mayor rigor el segundo, en tanto que en el intervencionismo por parte del Estado, se aplica con mayor intensidad el derecho administrativo, pero, sin abandonar el derecho privado. Esto lo resume Barón (2016): “Tanto en neoliberalismo como en el intervencionismo de estado se aplica el derecho público y privado, cuya sumatoria es el derecho económico" (p. 33).

Del acto administrativo también ha sido objeto de estudio de este fenómeno. El profesor de la Universidad Sergio Arboleda (Santa Marta) Berrocal Guerrero (2016) ha señalado que es posible analizar la incidencia o los efectos de dicha huida sobre el acto administrativo, explicando que las tendencias privatizadoras del derecho han significado pérdida de espacio para los actos administrativos, a la par que lo ha ido perdiendo también el derecho adminis- 
trativo, en cuanto que, "muchas relaciones, que antes eran legales y reglamentarias, entre ellas las que se dan en el campo laboral, están pasando a ser de derecho privado" (p. 17).

El mencionado autor señala otro ejemplo de los efectos de este fenómeno sobre los actos administrativos, el de los actos unilaterales de entes estatales que vienen siendo sustituidos por los actos privados de quienes pasan a reemplazar a esos entes en la función administrativa, verbigracia, los servicios públicos domiciliarios; obviamente que dichos actos unilaterales deben observar los principios de la función administrativa, principios propios de derecho público.

Las anotaciones precedentes nos permiten afirmar que el derecho económico, como un nuevo paradigma de las ciencias sociales, surge a partir de la influencia recíproca entre normas de derecho público y normas de derecho privado.

Pasemos ahora a tratar los temas sobre a) la noción doctrinal, b) el carácter autónomo y c) las fuentes de la institución derecho económico.

\subsection{Definición doctrinal de la institución: derecho económico}

Varias han sido las definiciones que la doctrina ha desarrollado referentes al derecho económico. Algunos lo han determinado como el derecho de la intervención del Estado en la economía (Ariño, 2003), o como el derecho mixto con relación al derecho público y al derecho privado (Barón, 2016).

El argentino Farina (1999) ofrece una definición que a nuestro juicio es más precisa, puesto que lo entiende como

El conjunto de normas que rigen la organización de la economía por los poderes públicos y regulan las actividades económicas de las personas privadas y del Estado, a fin de dar cumplimiento a la política económica puesta en práctica por el Estado. (p. 46)

La definición proporcionada por Farina (1999) guarda estrecha relación con la institución: Intervención del Estado en la economía, la cual forma parte del campo de estudio de la política económica. Esta teoría hace parte del derecho económico (Vidal, 2004) y es uno de los temas transcendentales de la Constitución económica (Sánchez, 2007). Según el ex gerente del Banco de la República seccional Ibagué, Hernández Quintero (1991), la intervención del Estado en la economía es "el conjunto de normas con las cuales se pretende regular y delimitar la autonomía de los particulares a fin de garantizar el logro de los intereses de la comunidad, esto es, el bien común" (p. 21). 
En el mismo sentido lo define el profesor español Ariño Ortiz (2003), al señalar que: "El derecho económico en su aceptación más extendida reuniría las normas e instrumentos jurídicos a través de los cuales el Estado dirige la actividad económica; fundamentalmente la Constitución económica, $\mathrm{y}$, como consecuencia, el derecho administrativo económico" (p. 67).

En este orden, el hacendista Ortega Cárdenas (2014) ha explicado que la intervención del Estado en la economía se justifica para alcanzar la equidad en la distribución y la riqueza nacional, cuando los mercados no pueden por sí solos alcanzar sus objetivos. Barón (2016) expone que las herramientas que sirven para intervenir en la economía son: a) la política económica y b) la planeación económica. La primera alude a las decisiones económicas para hacerle frente a la inflación y al desempleo; y, la segunda, se refiere a la forma deliberada que el Estado tiene para influir en las actividades económicas, de una manera eficiente, y obviamente con el mínimo de costo social.

De las consideraciones precedentes encontramos una evidente diferencia entre derecho administrativo y derecho económico; el primero comprende la regulación de la función administrativa de los órganos del Estado, e incluye aquellas funciones administrativas ejercidas por particulares autorizados por la ley, en tanto que el segundo contempla el estudio de la teoría de la intervención del Estado en la economía a través de la regulación (política económica).

Para finalizar este aparte, sobra mencionar que no debemos confundir el derecho económico con el derecho comercial. Este último es un Derecho Privado, pues, recordemos que "el Derecho Comercial y el Derecho Civil tienen un mismo tronco o causa común: el derecho privado" (Linares, 2001, p. 29); mientras que el primero, se repite, es un derecho híbrido con relación al derecho público y al derecho privado. Ambos son dinámicos, evolucionan aceleradamente, por su naturaleza y condiciones de las actividades económicas de los particulares y del Estado.

\subsubsection{El carácter autónomo del derecho económico}

La autonomía del derecho económico ha sido objeto de discusiones en la doctrina; algunos aceptan su carácter autónomo, otros no. Nosotros compartimos el criterio de Barón (2016), quien acepta su carácter autónomo.

Barón (2016) señala que el derecho económico efectúa "una influencia recíproca entre derecho público y privado, convirtiéndose de esta manera en una rama autónoma del derecho, autónoma porque al aplicar las dos ramas del derecho corrige las inexactitudes que se presentan al aplicar una rama por separado" (p. 42). 
Compartimos el criterio que ofrece Barón porque si observamos, por ejemplo, el derecho de los servicios públicos domiciliarios (Ley 142 de 1994), en materia contractual su régimen jurídico es prevalentemente el derecho privado (normas civiles y comerciales), pero no excluye la aplicación de normas y principios de derecho público (Atehortúa, 2017), aplicación híbrida de normas tanto de derecho privado como las de derecho público, que confiere al derecho económico su autonomía; de esa manera, se vale de dicho carácter para hacer uso de la pluralidad de principios que determinan su propia naturaleza económica.

\subsubsection{Fuentes del derecho económico}

Las fuentes del derecho económico son las mismas que rigen las demás áreas del derecho, como la Constitución Política, la ley, los decretos, los principios, la jurisprudencia (precedente judicial), la doctrina.

La Constitución es, sin duda, la principal fuente del ordenamiento jurídico. Las normas inferiores a ella deben estar sometidas por principios constitucionales. De lo anterior surge el fenómeno difundido por la doctrina, denominado la constitucionalización del derecho (Montaña, 2017).

Barón (2016) afirma que la fuente principal del derecho económico es el acto administrativo. Sin embargo, creemos que también lo es el contrato estatal, el celebrado por el Estado y, que, de acuerdo con el artículo 1602 del Código Civil, es Ley para las partes.

Es importante mencionar de nuevo que en los contratos estatales se deben aplicar normas de derecho público y de derecho privado, aplicación mixta que equivale a derecho económico; de ahí la importancia que cobra la teoría económica en los mencionados negocios; teniendo en cuenta, además, que "el contrato es la fuente más importante de las obligaciones y es el único medio para el desarrollo de las actividades económicas del Estado" (Forero, 2017, p. 44).

\section{Del Banco de la República. Aspectos generales}

\subsection{Las principales características del Banco de la República a partir de la} Constitución Política de Colombia de 1991

Una de las responsabilidades más importantes que tiene el Banco de la República es la estabilidad de la moneda, pues, tal como lo explica el profesor de la Universidad Libre, Marín Vélez (2016), por expreso mandato del Constituyente de 1991, el mencionado Banco asume la responsabilidad de velar por el mantenimiento de la capacidad adquisitiva de la moneda; es decir, controlar la inflación, como objetivo principal de la política monetaria. 
La inflación, de acuerdo con el tratadista en derecho monetario Chacón Álvarez (2005), es "el constante aumento de los precios de una economía" (p. 50 ), es decir, hay inflación cuando los precios de los bienes y servicios aumentan constantemente.

En relación con lo anterior, es importante seguir las enseñanzas del profesor Hernández (2011), quien señala que la falsificación de moneda implica también inflación, pues, afecta su poder adquisitivo; y, en consecuencia, el Banco de la República puede constituirse como parte civil — víctima — en los procesos penales que se adelantan por falsificación de moneda (Hernández, 2015).

Podemos resumir las principales características del Banco de la República a partir de la Constitución de 1991 de la siguiente manera:

En la Asamblea Nacional Constituyente se presentaron dieciocho proyectos relacionados con la teoría de la Banca Central, aquellos que estudiados, compendiados, modificados dieron origen a los artículos 371, 372 y 373; normas constitucionales que elevaron al Banco de la República a la categoría de órgano estatal constitucional autónomo (Chacón, 2005). Es de anotar que la historia del Banco de la Republica se inicia con la Ley 25 de 1923, y adopta las recomendaciones de la Misión Kemmerer (Álvarez, 2012).

El artículo 371 constitucional indica que el Banco de la República estará organizado como: 1) persona jurídica de derecho público; 2) con autonomía administrativa; 3) con autonomía patrimonial; 4) con autonomía técnica; 5) sujeto a un régimen legal propio. Se señalan funciones básicas como: a) regular la moneda, los cambios internacionales y el crédito, b) la emisión de la moneda legal, c) la administración de las reservas internacionales, d) ser prestamista de última instancia y banquero de los establecimientos de crédito y f) servir como agente fiscal del Gobierno; funciones que son ejercidas, por mandato del Constituyente, en "coordinación con la política económica general" (artículo 371 de la Constitución Política, 1991).

En relación con la expresión "coordinación con la política económica general", de acuerdo con el artículo $4^{\circ}$ de la Ley 31 de 1992, las funciones arriba mencionadas se ejercerán en coordinación prevista en el programa macroeconómico aprobado por el Consejo Nacional de Política Económica y Social (CONPES), "siempre que esta no comprometa la responsabilidad constitucional del Estado, por intermedio del Banco de la República, de velar el mantenimiento de la capacidad adquisitiva de la moneda" (Gaviria, 1999, p. 47).

El artículo 372 constitucional alude a la Junta Directiva del Banco de la República, que reemplazó a la anterior Junta Monetaria; posee la categoría de 
autoridad monetaria, cambiaria y crediticia, y le asigna la competencia para la dirección y ejecución de las funciones del Banco de la República.

La norma en cita establece la conformación de la Junta Directiva, que estará compuesta como órgano colegiado de siete miembros: El ministro de Hacienda y Crédito Público (quien la preside), el gerente general del Banco y cinco miembros de dedicación exclusiva; estos últimos son nombrados por el presidente de la Republica, mientras que el gerente lo es por los restantes miembros de la Junta. Se les asigna como característica especial la de representar "exclusivamente el interés general de la Nación" (artículo 372 de la Constitución Política, 1991).

Del alcance y contenido de la expresión: "Los miembros de la Junta Directiva representarán exclusivamente el interés de la Nación" (artículo 372 de la Constitución Política, 1991) consiste, de acuerdo con Chacón (2005), en que "las decisiones que adopte la Junta Directiva, como autoridad del Estado y en forma colegiada, deben corresponder al estimativo que hace sus miembros como las más oportunas y requeridas para el país" (p. 241).

El Congreso de la República, en virtud del numeral 22 del artículo 150 de la Constitución Política, dictará la ley a la cual deberá ceñirse al Banco para el ejercicio de sus funciones y las normas con sujeción a las cuales el Gobierno expedirá los Estatutos del Banco.

El legislador por orden del constituyente expidió la Ley 31 de 1992:

Por la cual se dictan las normas a las que deberá sujetarse el Banco de la República para el ejercicio de sus funciones, el Gobierno para señalar el régimen de cambio internacional, para la expedición de los Estatutos del Banco y para el ejercicio de las funciones de inspección, vigilancia y control del mismo, se determinan las entidades a las cuales pasarán los Fondos de Fomento que administra el Banco y se dictan otras disposiciones. (Gaviria, 1999, p. 47)

El 14 de diciembre de 1993 el presidente de la República en ejercicio de las facultades señaladas en el artículo 372, con sujeción a las normas de la Ley 31 de 1992, emitió el Decreto 2520, "Por el cual se expide los Estatutos del Banco de la República" (Gaviria, 1999, p. 70). Este ha sufrido modificaciones por los Decretos 2867 de 2001 y 1458 de 2004.

\subsection{El Banco de la República como persona jurídica de derecho público}

Dijimos que el Banco de la República es una persona jurídica de derecho público. De acuerdo con Chacón (2005), el Banco Central como persona jurídica goza de los atributos propios de la personalidad como son: a) nombre, b) do- 
micilio, c) capacidad, d) patrimonio y e) nacionalidad. Es pertinente explicar dos de dichos atributos: La capacidad y el patrimonio.

El Banco de la República goza de plena capacidad jurídica para adquirir derechos y contraer obligaciones dentro del ámbito de sus funciones. Chacón (2005), explica que, al poseer capacidad jurídica, el Banco puede suscribir contratos, expedir actos administrativos, actuar como demandante, ser demandado en procesos judiciales, en fin.

En cuanto al patrimonio, de acuerdo con el artículo 371 constitucional, el Banco Central cuenta con autonomía patrimonial, es decir, su patrimonio es propio y no depende del Presupuesto General de la Nación; sus ingresos y egresos están previstos en el Presupuesto que anualmente aprueba la Junta Directiva (Chacón, 2005).

\subsection{De las funciones básicas de regulación monetaria, cambiaria y crediticia}

Habíamos mencionado que, de acuerdo con el artículo 371 constitucional, en coordinación con la política económica general, el Banco de la República, a través de la Junta Directiva, ejerce funciones básicas, entre otras: regular: a) la moneda, b) los cambios internacionales y c) el crédito. Es necesario explicar estas funciones, que se manifiestan a través de actos administrativos, como modalidades de intervención del Estado en la economía (Rivero, 2001).

La función monetaria tiene por finalidad el control de la cantidad de dinero en circulación (Martínez, 2004). A través de su utilización se disminuye o se aumenta tal cantidad según las necesidades, o el comportamiento, de la economía (Gaviria, 1999). De la facultad monetaria encontramos: 1) el encaje, 2) operaciones de mercado abierto (OMA), 3) señalar límites de crecimiento de la cartera de crédito, y 4) dar concepto previo favorable para amortizar excedentes transitorios de divisas provenientes de exportaciones de bienes por empresas públicas (Chacón, 2005).

La función o facultad cambiaria tiene como finalidad la regulación de las divisas o monedas extranjeras en Colombia, y la salida física de moneda nacional del territorio colombiano (Martínez, 2004). Forma parte también la regulación de tasa de cambio o relación entre el peso en relación con el dólar americano: "Por estar el país dentro de la zona de influencia americana en razón de que su comercio exterior, las inversiones extranjeras y las deudas externas pública y privada están establecidas en la moneda americana" (Chacón, 2005, p. 356). 
La función crediticia tiene que ver con el costo del dinero (Hernández, 2004) y hace referencia a las tasas de interés (Martínez, 2004). Es importante tener en cuenta que la Junta Directiva, en situaciones muy excepcionales, como cuando la economía se derrumbara (Chacón, 2005), puede regular de manera impositiva las tasas máximas de intereses remuneratorios en operaciones activas y pasivas y de las tasas máximas de intereses en operaciones en moneda extranjera, según lo prevé el literal e) del artículo 16 de la Ley 31 de 1992 (Gaviria, 1999).

Es de mencionar que el Banco de la República no es la única autoridad monetaria, cambiaria y crediticia, toda vez que algunas de dichas funciones son ejercidas también por el Congreso de la República y por el Gobierno (Martínez, 2004).

Señalábamos que las citadas facultades del Banco Central se manifiestan a través de actos administrativos; entonces, enseguida se abordará el régimen jurídico de los actos administrativos del mencionado Banco para concluir que no es conveniente hablar que dicho régimen es de derecho administrativo, sino de derecho económico.

\section{El régimen jurídico de los actos administrativos del Banco de la República, ¿derecho administrativo o derecho económico?}

Es muy común afirmar que el régimen jurídico de los actos administrativos del Banco de la República es de derecho administrativo. Nosotros afirmamos que es más de derecho económico y este, a su vez, es el derecho mixto que lo permea tanto el derecho público como el derecho privado, o como el derecho de la intervención del Estado en la economía.

En esta oportunidad exponemos la relación del régimen jurídico de los actos administrativos del Banco de la República con las nociones de la institución derecho económico como 1) el derecho mixto con relación al derecho privado y al derecho público y como 2) el derecho de la intervención del Estado en la economía, para ultimar que no es conveniente hablar de derecho administrativo cuando nos referimos al régimen jurídico de los actos del citado Banco, sino propia y apropiadamente de derecho económico.

\subsection{Desde la noción del derecho económico como el derecho mixto que lo permea tanto el derecho público como el derecho privado}

De acuerdo con la Ley 31 de 1992, desde el régimen jurídico de los actos administrativos y de los contratos del Banco de la República se tratarán de actos 
administrativos sometidos al derecho administrativo cuando sean funciones públicas; $\mathrm{y}$ de actos y contratos privados, en el evento de relaciones jurídicas comerciales, civiles y laborales. Pues, el artículo $3^{\circ}$ de la Ley 31 establece que, como consecuencia del régimen legal propio del Banco, las operaciones mercantiles y civiles, y en general, los actos del Banco que no fueren administrativos, se regirán por las normas de derecho privado.

Los actos administrativos expedidos por la Junta Directiva del Banco pueden clasificarse como actos administrativos particulares y generales. Dichos actos deberán ser firmados por el presidente y el secretario de la Junta y se comunicarán y notificarán de acuerdo con la naturaleza de la decisión que contengan (Marín, 2016). Los demás actos y contratos, se reitera, se regirán por las normas de derecho privado.

Las decisiones que emita la Junta Directiva en calidad de máxima autoridad monetaria, cambiaria o crediticia, son actos administrativos de carácter general e impersonal que reciben la denominación de Resoluciones externas. Las decisiones que se adoptan en relación con las dependencias internas del Banco de la República se denominan como Resoluciones Internas.

Los actos administrativos de carácter general deberán publicarse en el Boletín que la Junta Directiva autorice para este objeto; así lo prevé el literal a) del artículo 51 de la Ley 31 de 1992 (Gaviria, 1999). Actos administrativos sometidos al control judicial del Consejo de Estado, a través de los medios de control (Palacio, 2000). Sobra anotar que una de las diferencias que podemos encontrar en las nulidades del derecho privado y las del derecho público es la antinomia entre la autonomía de la voluntad y el interés general (Saborío, 2002).

Cuando los actos administrativos sean de contenido particular, es decir, cuyo contenido tiene un destinatario individualizado (o destinatarios individualizados), estos serán motivados; es de ejecución inmediata; deben estar notificados según las reglas señaladas en la Ley 1437 de 2011; susceptibles de recursos de la vía administrativa (o vía gubernativa, si prefiere), recursos que se concederán en efecto devolutivo.

Respecto de la publicación, cuando el acto administrativo es general, y de la notificación, cuando el acto es particular, la doctrina ha explicado que la eficacia del acto administrativo suele sustentarse tanto en la publicación y como en la notificación, pues de esta manera puede producir la totalidad de las consecuencias jurídicas para las cuales fue producido (Rico, 2013).

Hasta aquí es fácil afirmar que el régimen jurídico de los actos administrativos del Banco de la República es de derecho administrativo, pero es im- 
portante tener en cuenta que dichos actos jurídicos no se escapan en cuanto a su aplicación instituciones de derecho privado, como son: a) la teoría del acto jurídico, b) de la personalidad jurídica y c) de la irretroactividad; de ahí que la aplicación híbrida de normas de derecho público y de derecho privado en el citado régimen jurídico nos conduce a señalar que no es conveniente hablar de derecho administrativo, sino de derecho económico.

De la teoría del acto jurídico. Al revisar varios libros sobre la materia se ha identificado que el acto administrativo tradicionalmente se ha asociado a la noción del acto jurídico (Penagos, 1992), es decir, al de la manifestación de voluntad (Sánchez, 1995); al comprender por acto jurídico, según el profesor de la Universidad Libre, Cardona Hernández (2001), como "toda declaración de voluntad libre, consciente y reflexiva encaminada a producir efectos en derecho" (p. 11). No hay que confundir el acto jurídico con el hecho jurídico; donde hay voluntad hay un acto, y donde no hay voluntad hay un hecho.

De la teoría de la manifestación de voluntad facilitó a la doctrina del derecho público para la elaboración de la noción del acto administrativo, como "manifestación unilateral de voluntad de quienes ejercen funciones administrativas, tendiente a la producción de efectos jurídicos" (Santofimio, 1998, p. 129). Noción bastante compartida por la doctrina especializada.

Es por ello que la doctrina ha incluido la voluntad administrativa dentro de los elementos esenciales del acto administrativo (Rico, 2014). El Consejo de Estado, en su reiterada Jurisprudencia, también ha señalado que la voluntad administrativa es otro elemento esencial del acto administrativo, es la existencia de una voluntad estatal válida, exteriorizada en una declaración expresada en forma legal (Younes, 2016).

Importante es tener en cuenta que la validez del acto administrativo, de acuerdo con el tratadista argentino Agustín Gordillo (2011), predica también en la ausencia de vicios de la voluntad, es decir, ausencia de error, fuerza y dolo, y son figuras propias de derecho privado (Sánchez, 1995).

De la teoría de la personalidad jurídica. En el derecho civil, de acuerdo con el artículo 633 del Código Civil, la persona jurídica es aquella persona ficticia con capacidad jurídica para "ejercer derechos y contraer obligaciones civiles, y de ser representada judicial y extrajudicialmente" (Castro, Tafur \& Contreras, 1994, p. 531).

En el derecho administrativo el Estado es una persona jurídica capaz de adquirir derechos y contraer obligaciones (Rodríguez, 2000). De la personalidad jurídica del Estado, el profesor de la Universidad Externado de Colombia, 
Santofimio Gamboa (1998), ha explicado que "En la práctica, todo el sector central de la administración nacional actúa por ser órgano de la persona jurídica nación (Estado). El sector descentralizado posee cada uno de sus organismos personería jurídica propia" (p. 42).

En relación con el Banco de la República, dijimos que el citado Banco es una persona jurídica de derecho público, órgano que goza de los atributos propios de la personalidad como: nombre, domicilio, capacidad, patrimonio y nacionalidad. Uno de los importantes atributos es la plena capacidad jurídica para adquirir derechos y contraer obligaciones dentro del ámbito de sus funciones; el Banco Central puede suscribir contratos, expedir actos administrativos, actuar como demandante, y ser demandado en procesos judiciales, en fin.

De la teoría de la irretroactividad de los actos administrativos. De acuerdo con el costarricense Saborío Valverde (2002), debemos observar la regla según la cual el acto administrativo producirá efecto únicamente para el futuro. No menos importante es mencionar que en aplicación de la citada teoría se debe respetar los derechos adquiridos, pues estos no podrán ser modificados por un acto administrativo posterior a su materialización (Penagos, 1992).

Igualmente, encontramos otras figuras propias de derecho privado las cuales permiten purgar los vicios del acto administrativo, como son: 1) la convalidación (cuando el acto que se expide resulta violatoria y que con posterioridad aquella es modificada o derogada), 2) la conversión (consiste en la trasformación del acto viciado en un acto nuevo y distinto, que aprovecha elementos validos del primer acto y las incorpora en el nuevo acto) y 3) la conservación (opera cuando la contradicción con el orden jurídico es parcial o cuando el vicio no sea trascendente) (Rico, 2014).

Las consideraciones precedentes nos permiten afirmar que el régimen jurídico de los actos administrativos del Banco de la República es de derecho económico toda vez que se aplican instituciones de derecho público y de derecho privado.

\subsection{Desde la noción del derecho económico como el derecho de la intervención del Estado en la economía}

Encontramos otros factores los cuales nos permiten afirmar que el régimen jurídico de los actos administrativos del citado Banco es más de derecho económico que de derecho administrativo: 1) Por ser el Banco de la República uno de los partícipes de la intervención del Estado en la economía y 2) por la influencia política y económica contenida en las decisiones tomadas por el 
citado Banco; estos dos factores conservan estrecha relación con una de las definiciones de derecho económico citadas en este trabajo, que es el derecho de la intervención del Estado en la economía.

Cuando el Banco de la Republica, a través de la Junta Directiva, regule materias monetaria, cambiaria y crediticia, se repiten, a través de actos administrativos (Resoluciones externas), dichas regulaciones; de acuerdo con el tratadista español Rivero Ortega (2001), son por excelencia modalidades de intervención del Estado en la economía, y forman parte del campo de estudio del derecho económico (Vidal, 2004).

De lo anterior, surge la importancia que cobra el estudio de la teoría económica en los actos administrativos de regulación económica que contribuyen en el desarrollo económico de un país; actos jurídicos los cuales son factibles de ser analizados a través de la metodología Análisis Económico del Derecho (AED), que también hace parte del derecho económico (Barón, 2016); metodología que consiste en la aplicación de la teoría económica en las instituciones jurídicas (Arrubla, 2009).

En este orden de ideas, el mencionado Banco se convierte en uno de los protagonistas importantes de la intervención en la economía. Sobra mencionar que la regulación económica está definida, siempre, para dar respuesta a los problemas y necesidades de los agentes económicos, y por tal razón toda regulación tiene unos objetivos concretos (criterio finalista).

Por el otro lado, cuando el Banco de la República, a través de la Junta Directiva, al expedir actos administrativos sus contenidos, además de ser la concreción de la función administrativa (Sánchez, 1995), tienen influencia de carácter político y económico; el primero porque emana del ejercicio de poder, pues, el citado Banco está facultado para regular materias monetaria, cambiaria y crediticia sin necesidad de un previo concepto o autorización de los demás órganos; es por ello que el Constituyente de 1991, gústenos o no, fue estricto en señalar que el citado Banco será autónomo.

Y económico, pues, sus decisiones están relacionadas, sin duda, con la economía, están conectadas con la estabilidad de la moneda, contribuyen en el desarrollo económico de un país. Además, implican, o contienen, consecuencias en el curso de la economía (Álvarez, 2012).

Las decisiones económicas tomadas por el Banco de la República siempre están relacionadas con el tema de la estabilidad de la economía, situación que consiste, de acuerdo con el profesor Ortega (2014), "en evitar cambios bruscos en ciertas variables y tiene como sus principales propósitos los controles al desempleo, la recesión y la inflación” (p. 73). 
La estabilidad económica es una de las tantas razones de la intervención estatal en la economía, en búsqueda del bienestar de la colectividad ante la presencia de los problemas del mercado (Hernández, 1991). Por eso se dice que la intervención del Estado en la economía está orientada al logro de la estabilidad económica.

Tenemos, entonces, que el derecho económico no solamente es el derecho mixto con relación al derecho público y al derecho privado, sino también es el derecho de la intervención del Estado en la economía. Lo anterior nos permite afirmar, y está demostrado, que el régimen jurídico de los actos administrativos del Banco de la República es de derecho económico.

\section{Conclusiones}

- El derecho económico es definido como el derecho híbrido con relación al derecho público y al derecho privado; también es definido como el derecho de la intervención del Estado en la economía. En tanto que el derecho administrativo es el derecho de la Administración pública o de la función administrativa.

- El Banco de la República es una persona jurídica de derecho público, que cuenta con autonomía: 1) administrativa, 2) patrimonial y 3) técnica; ejerce funciones, a través de la Junta Directiva, en coordinación de la política económica general, entre otras: regular materias: a) monetaria, b) cambiaria y c) crediticia, facultades que se manifiestan a través de actos administrativos, actos jurídicos en los cuales se le deben aplicar instituciones de derecho público y de derecho privado.

- Se concluye sin rodeos, y está comprobado, que el régimen jurídico de los actos administrativos del Banco de la República es de derecho económico por la aplicación híbrida de instituciones de derecho público y de derecho privado en los actos administrativos.

- Es también derecho económico el citado régimen jurídico por cuanto las regulaciones en materias: monetaria, cambiaria y crediticia, que se manifiestan a través de actos administrativos (Resoluciones externas), son por excelencia modalidades de intervención del Estado en la economía en búsqueda del bienestar de la colectividad ante la presencia de los problemas del mercado. 


\section{Referencias}

Álvarez Didyme-dôme, M. J. (2012). Contratos mercantiles (1 ${ }^{a} E d$.). Ibagué, Colombia: Ediciones Unibagué.

Amado Abril, J. H. (2017). Del Derecho Administrativo Global [notas de clase]. Maestría en Derecho Administrativo. Pereira, Colombia: Universidad Libre.

Arrubla Paucar, J. A. (2009). Contratos mercantiles contemporáneos $\left(2^{a} E d\right.$.). Medellín, Colombia: Ediciones Biblioteca Jurídica DIKÉ.

Ariño Ortiz, G. (2003). Principios de Derecho Público Económico (1 ${ }^{a}$ Ed.). Bogotá, Colombia: Ediciones Universidad Externado de Colombia.

Atehortúa Ríos, C. A. (2017). Teoría económica en el régimen jurídico de los servicios públicos domiciliarios [notas de clase]. Maestría en Derecho Administrativo. Pereira, Colombia: Universidad Libre.

Ayala Caldas, J. E. (1994). Elementos del Derecho Administrativo colombiano $\left(1^{a}\right.$ Ed.). Bogotá, Colombia: Ediciones Doctrina y Ley Ltda.

Ayala Caldas, J. E. (2009). Estructura de la rama ejecutiva en Colombia ( $1^{a}$ Ed.). Bogotá, Colombia: Ediciones Doctrina y Ley Ltda.

Barón Barrera, G. A. (2016). Transformación del derecho administrativo en derecho económico ( $1^{a} E d$.). Bogotá, Colombia: Ediciones de la U.

Berrocal Guerrero, L. E. (2016). Manual del acto administrativo ( $7^{a} E d$.). Bogotá, Colombia: Ediciones Librería del Profesional Ltda.

Cardona Hernández, G. (2001). Curso de obligaciones ( $1^{a} E d$.). Bogotá, Colombia: Ediciones Doctrina y Ley Ltda.

Cassagne, J. C. (1999). Derecho Administrativo Tomo I $\left(7^{a} E d\right.$.). Buenos Aires, Argentina: Ediciones Lexis Nexis.

Castro Guerrero, A., Tafur González, Á. y Contreras Restrepo, G. (1994). Código Civil. Comentado ( $4^{a} E d$.). Bogotá, Colombia: Editorial Leyer.

Chacón Álvarez, N. R. (2005). Derecho monetario ( $\left(1^{a} E d\right.$.). Bogotá, Colombia: Ediciones Librería Ediciones del Profesional Ltda.

Farina, J. M. (1999). Contratos comerciales modernos $\left(2^{a} E d\right.$.). Buenos Aires, Argentina: EdicionesEditorial ASTREA de Alfredo y Ricardo Depalma.

Forero Hernández, C. F. (2017). Los riesgos y la ecuación económica del contrato estatal. En Temas y reflexiones No. 5 (pp. 43-57). Ibagué, Colombia: Ediciones Unibagué.

Fraga, G. (2000). Derecho Administrativo. Revisada y actualizada por Manuel Fraga ( $4^{a} E d$.). Polanco, México: Ediciones Editorial Porrúa.

Gaviria Cadavid, F. (1999). Moneda, Banca y Teoría Monetaria $\left(5^{a} E d\right.$.). Bogotá, Colombia: Ediciones Fundación Universidad de Bogotá Jorge Tadeo Lozano. 
Gordillo, A. (2011). El acto administrativo (10 ${ }^{a}$ Ed.). Buenos Aires, Argentina: Ediciones Fundación Derecho Administrativo.

Guerrero Orozco, O. (1997). Principios de la Administración Pública (1 ${ }^{a}$ Ed.). Bogotá, Colombia: Ediciones Escuela Superior de Administración Pública, ESAP.

Hernández Quintero, H. A. (1991). De los delitos económicos en la actividad financiera ( $1^{a} E d$.). Bogotá, Colombia: Escuela Judicial Rodrigo Lara Bonilla.

Hernández Quintero, H. A. (2004). Del delito de usura. Monografia (1 ${ }^{a}$ Ed.). Bogotá, Colombia: Editorial Ibáñez.

Hernández Quintero, H. A. (2011). Falsificación de moneda. En Derecho Penal. Parte especial (pp. 907-930). Bogotá, Colombia: Ediciones Universidad Externado de Colombia.

Hernández Quintero, H. A. (2015). Los delitos económicos en la actividad financiera ( $7^{a} E d$.). Bogotá, Colombia: Ediciones Editorial Ibáñez.

Linares Vesga, J. Á. (2001). Curso de Derecho Comercial. Actualizado (1 ${ }^{a}$ Ed.) Bogotá, Colombia: Editorial Ibáñez.

Marín Vélez, M. (2016). Temas fundamentales del Derecho Administrativo colombia$n o\left(1^{a} E d\right.$.). Bogotá, Colombia: Ediciones Ibáñez-Universidad Libre.

Martínez Neira, N. H. (2004). Cátedra de Derecho Bancario colombiano (2 ${ }^{a}$ Ed.). Bogotá, Colombia: Ediciones Editorial Legis.

Molina Betancur, C. M. (2007). La contratación estatal: Entre derecho público y privado. En Los Contratos en el Derecho Privado ( $1^{a} E d$.). Bogotá, Colombia: Editorial Legis, 721-750.

Montaña Plata, E. A. (2017). Fundamentos de Derecho Administrativo [notas de clase]. Especialización en Derecho Administrativo. Ibagué, Colombia: Universidad de Ibagué.

Ortega Cárdenas, A. (2014). Hacienda Pública. Las finanzas del Estado (5 ${ }^{a}$ Ed.). Bogotá, Colombia: Ecoe Ediciones.

Palacio Hincapié, J. Á. (2000). Derecho Procesal Administrativo (2 ${ }^{a}$ Ed.). Medellín, Colombia: Ediciones Librería Jurídica Sánchez Ltda.

Penagos Vargas, G. (1992). El acto administrativo ( $5^{a}$ Ed.). Bogotá, Colombia: Ediciones Librería del Profesional.

Rico Puerta, L. A. (2013). El acto administrativo ( ${ }^{a}$ Ed.). Medellín Colombia: Ediciones Sello Editorial Universidad de Medellín.

Rivero Ortega, R. (2001). Introducción al derecho administrativo económico (2 ${ }^{a}$ Ed.). Salamanca, España: Ediciones Ratio Legis. 
Rivero, J. (2006). Derecho Administrativo ( $9^{a} E d$.). Traducido por la Facultad de Ciencias Jurídicas y Políticas de la Universidad Central de Venezuela. París, Francia: Ediciones Dalloz.

Rodríguez Rodríguez, L. (2000). Derecho Administrativo. General y colombiano $\left(12^{a}\right.$ $E d$.). Bogotá, Colombia: Editorial Temis.

Saborío Valverde, R. (2002). Eficacia e invalidez del acto administrativo (3 ${ }^{a}$ Ed.). San José, Costa Rica: Editorial Juricentro.

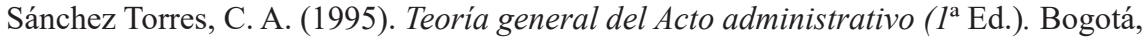
Colombia: Ediciones Biblioteca Jurídica Diké.

Sánchez Torres, C. A. (2007). Constitución Económica (1 ${ }^{a}$ Ed.). Bogotá, Colombia: Ediciones Escuela Judicial Rodrigo Lara Bonilla - Universidad Sergio Arboleda.

Santofimio Gamboa, J. O. (1998). Tratado de Derecho Administrativo. Tomos I y II (3 ${ }^{a}$ Ed.). Bogotá, Colombia: Ediciones Universidad Externado de Colombia.

Vidal Perdomo, J. (2004). Derecho Administrativo (12 ${ }^{a}$ Ed.). Bogotá, Colombia: Editorial Legis-Universidad del Rosario.

Younes Moreno, D. (2016). Curso de Derecho Administrativo (10 Ed.). Bogotá, Colombia: Editorial Temis.

\section{Bibliografía recomendada}

Barón Barrera, G. A. (2016). Transformación del derecho administrativo en derecho económico ( $1^{a} E d$.). Bogotá, Colombia: Ediciones de la U.

Chacón Álvarez, N. R. (2005). Derecho monetario ( $1^{a}$ Ed.). Bogotá, Colombia: Ediciones Librería Ediciones del Profesional Ltda.

Sánchez Torres, C. A. (1995). Teoría general del Acto administrativo (1 ${ }^{a}$ Ed.). Bogotá, Colombia: Ediciones Biblioteca Jurídica Diké. 